\title{
THE CHALLENGE OF DEVELOPING THAILAND'S MINERAL RESOURCES
}

by

\author{
Jim Harrison and Peter Leggo
}

\begin{abstract}
Two consultants - a geologist and a geochemist - express their views on the mineral potential of Thailand, some of the obstacles facing the country's future development of mineral resources, and the substantial regional benefits that international funding could realize through support of aerial techniques.
\end{abstract}

\section{Background}

The Government of Thailand, through its Department of Mineral Resources, requested a loan from the Asian Development Bank (ADB) to carry out a regional airborne geophysical survey of the country. Before granting the loan, the ADB decided that a small team of expatriates should examine whether or not an airborne geophysical survey was needed, and if it was, the team could then help the Department of Mineral Resources design an organization that could properly follow up on the results of the survey. Several companies were invited to make proposals about what should be done, and the contract for the preliminary investigation was awarded to Kenting Earth Sciences (Canada). Consulting geologist Jim Harrison was engaged as team leader for the project; Peter Leggo, a consulting geochemist from Cambridge, England, and John Irvine, a geophysicist with Kenting Earth Sciences made up the rest of the team. We spent about two months (June - July, 1981) in Thailand working with the staff of the Department of Mineral Resources; this paper summarizes some of our first-hand observations.

\section{Geological Activities}

The Ministry of Industry is the host ministry for the Department of Mineral Resources (DMR), and the organization is headed by a Director General. At present, he has some 14 different divisions reporting to him through the intermediary of three deputy directors general. The four divisions primarily concerned with what might be described as geological survey activities report through Dr. Sangob Kaewbaidhoon, a scientist well known for his work in geochemistry.

The Geological Map of Thailand is still in the reconnaissance stage. There are a few maps on a scale of $1: 250000$ and a few at 1:50 000 with a geological compilation of 1:1 000000 .

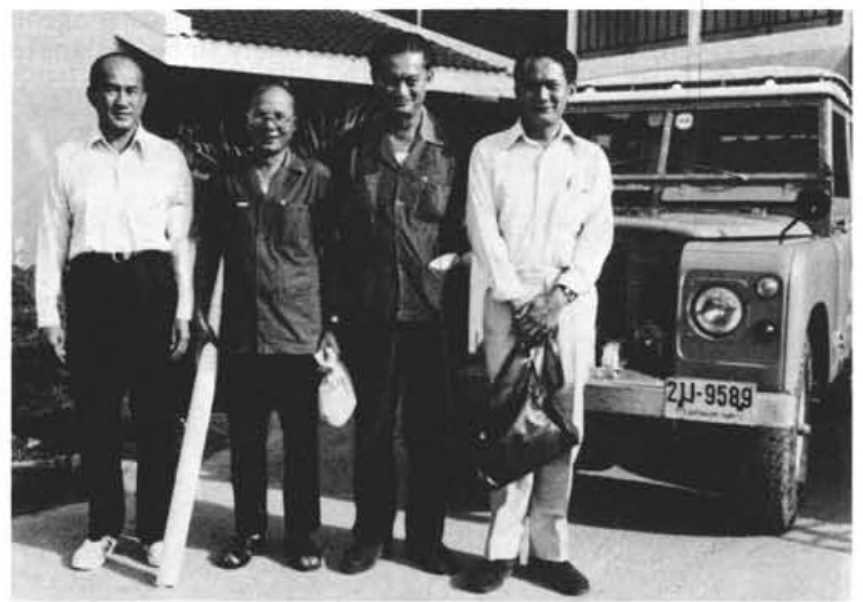

Gathered outside the headquarters building of the Department of Mineral Resources (DMR) in Chiang Mai are ( $L$ to $R$ ): Dr. Payome Aranyakanon, a senior expert with $D M R ; M r$. Phisit Thiradirok, regional geologist; Mr. Manas Veeraburus, the director of regional geology; Mr. Thawisak Danusawat, senior geophysicist.

EPISODES, Vol. 1981, No. 3.
Deep weathering, rough terrain and a heavy covering of vegetation make geological mapping very difficult, while in the central and northeastern plains of Thailand the deposits are covered by thick alluvium. Thus, an airborne geophysical survey should be of great assistance in determining some of the critical geological features of the country.

\section{Mineralization}

We found the country's mineral potential to be very good. There is abundant evidence of mineralization, the structure is complex and the geological features generally favour discovery of minerals. Severals deposits are known: tin has been mined mostly by open cuts, hydraulic techniques, and undersea dredging; sapphires and rubies have been known for centuries and are still being produced, but in relatively small quantities now; there are deposits of lead, zinc, copper, and iron, though few have been properly explored for commercial possibilities. Natural gas occurs in commercial quantities in the Gulf of Thailand and in the north, while small pools of oil have been discovered in the Gulf and in the northern part of the country.

The Khorat Plateau in the nor theast offers a great potential source of mineral wealth for Thailand. Here, very thick deposits of halite and carnallite are intermingled with some thick lenses and beds of sylvite. Unfortunately, the sylvite (which is about $50 \%$ potash) occurs in the lower parts of the sequence and seems to be in large lenses that have been tilted to an angle of about 30 degrees through diapiric action. The carnallite, which is only about 17 to $18 \%$ potash, is very abundant, and if it can be used, offers enormous quantities of fertilizer material for Thailand and the whole of SE Asia. Some very pure high-calcium limestones are known that could

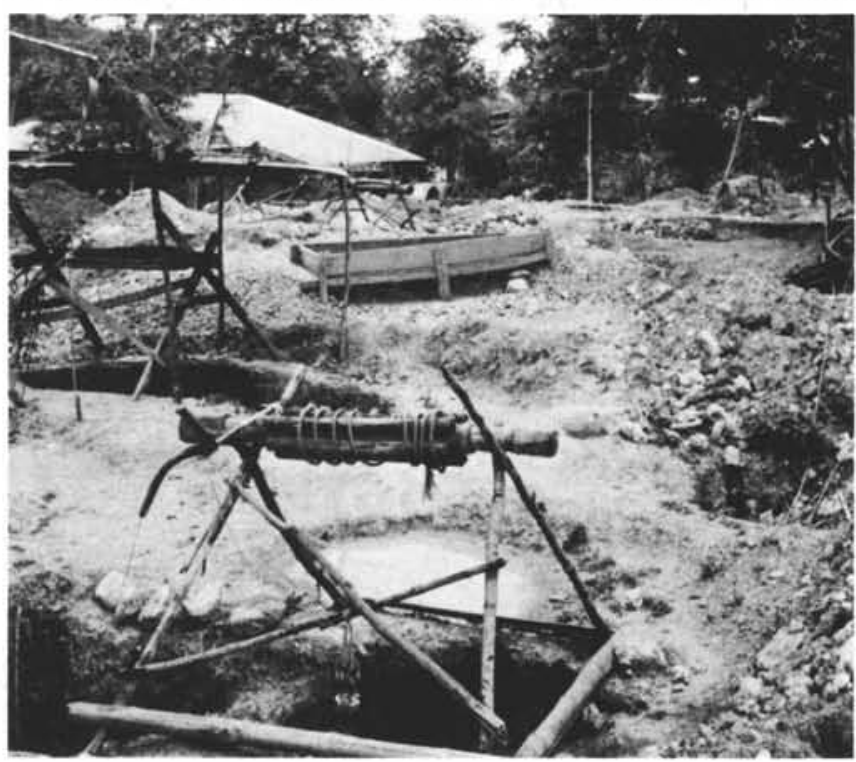

Sapphire mining, $w$. Thailand. 


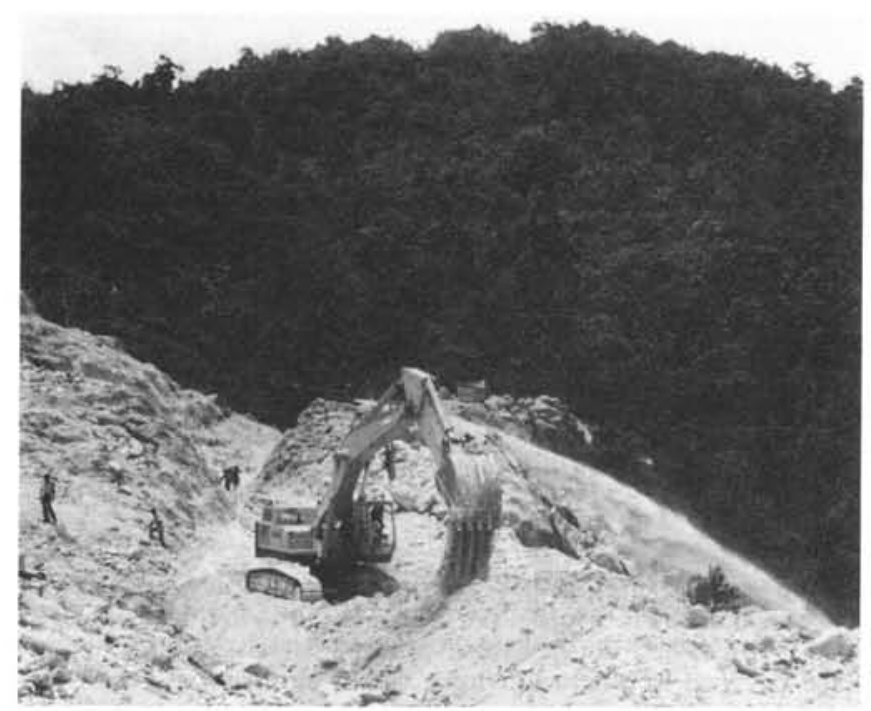

Weathered tin ore and sluice gun at the top of a mountain in $S$ Thailand.

be an excellent source of chemical CaO. Fluorite occurs in areas where hot springs now exist or have existed in the past, and clay materials are relatively abundant.

While the known coal deposits are small, the potential for geothermal energy is very impressive. Nearly 200 hot springs are known in Thailand and some of these merit detailed investigation through drilling. The first such study is planned for September 1981 near the northern provincial capital of Chiang Mai. Except for one coal-fired thermal station and one more being planned, all the current energy needs of Thailand are being supplied by imported oil. Useful geothermal energy sources would therefore be of great assistance to the country.

The drawbacks to the development of mineral resources, however, are numerous and burdensome. The bureaucracy governing administrative procedures is constrictive and tends to slow up progress unnecessarily. For example, practically all mineral leases are granted at ministerial discretion, so that potential foreign investors are reluctant to commit themselves to large-scale endeavours without having any clear indication of the terms under which the work will be carried out. The salaries paid in the bureaucracy are well below those paid in neighbouring countries, and in terms of salaries paid in some of the developed countries, they are really quite poor. It is difficult, therefore, to keep good people on staff who could contribute to the country's development.

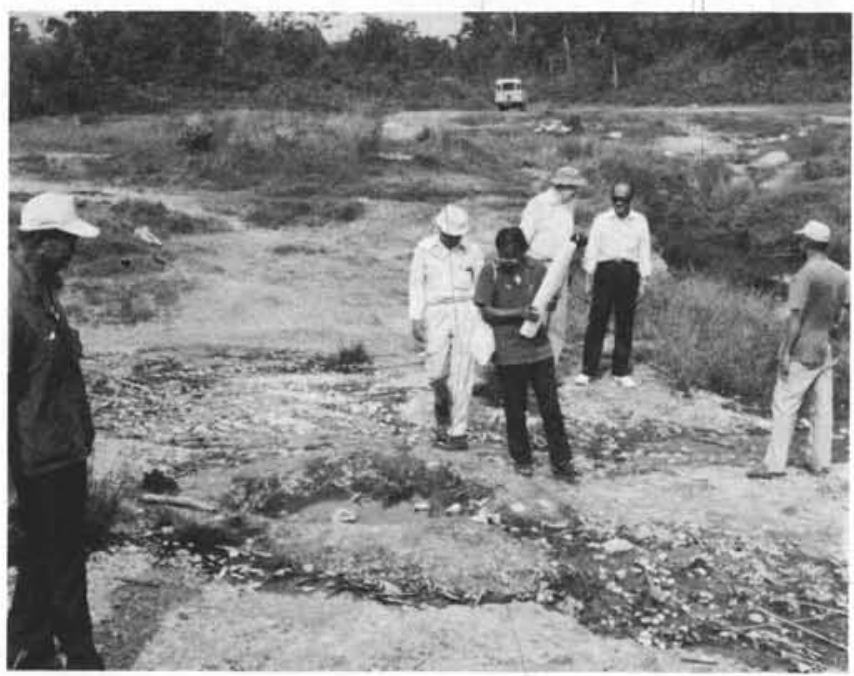

Hot springs near Chiang Mai, $N$ Thailand.

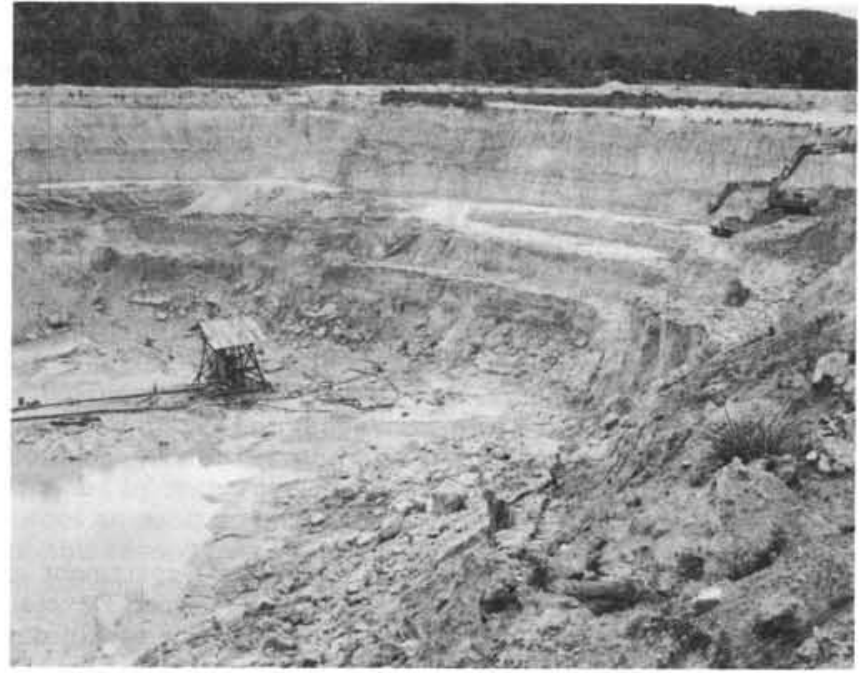

Tin mine in S Thailand.

At present, the amount of money available to the geological units is particularly small because of the financial difficulties of the country. As a result, there is little incentive for people either to work under the difficult field conditions of Thailand or to mount any worthwhile scientific projects. Foreign geological teams, especially from the U.S.A., the F.R.G. and the U.K., have all contributed substantially to the geological knowledge of Thailand, and the German missions in particular have produced useful maps. Publications of data obtained by the Thais themselves, however, are mostly in Thai and hence are little known to anyone outside the country. Nevertheless, we felt that a combination of the information already available, with the new data that will be provided through an airborne geophysical survey, would lead to excellent opportunities for discovery of new and useful mineral deposits.

\section{Remote Sensing}

The assemblage of data by remote sensing from satellites represents a substantial initiative. A receiving station is being constructed near Bangkok under the auspices of the National Research Council of Thailand (NRC), and the appropriate hardware to transform the data into hard copy is now being put in place. Because the satellite station will be receiving data related to all resources, the Thais are in a good position to attempt developing systems of informationhandling which will be common to all resource users. Whether this is in fact possible is doubtful, but the attempt should be made. Also, because NRC is the operating agency for the satellite receiving station, it is likely to be designated

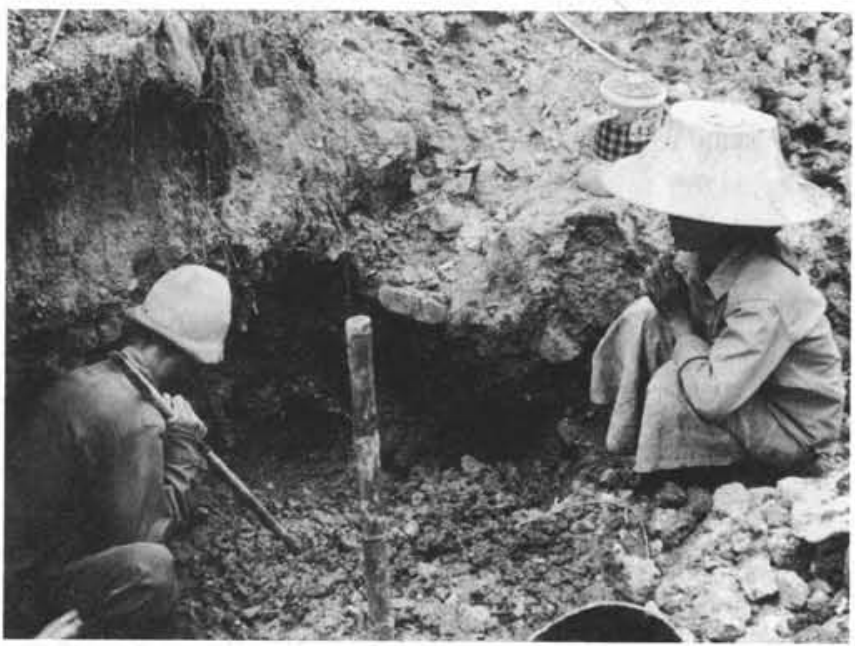

Sapphire mining near the world-famous "Bridge over the River Kwai", w Thailand. 

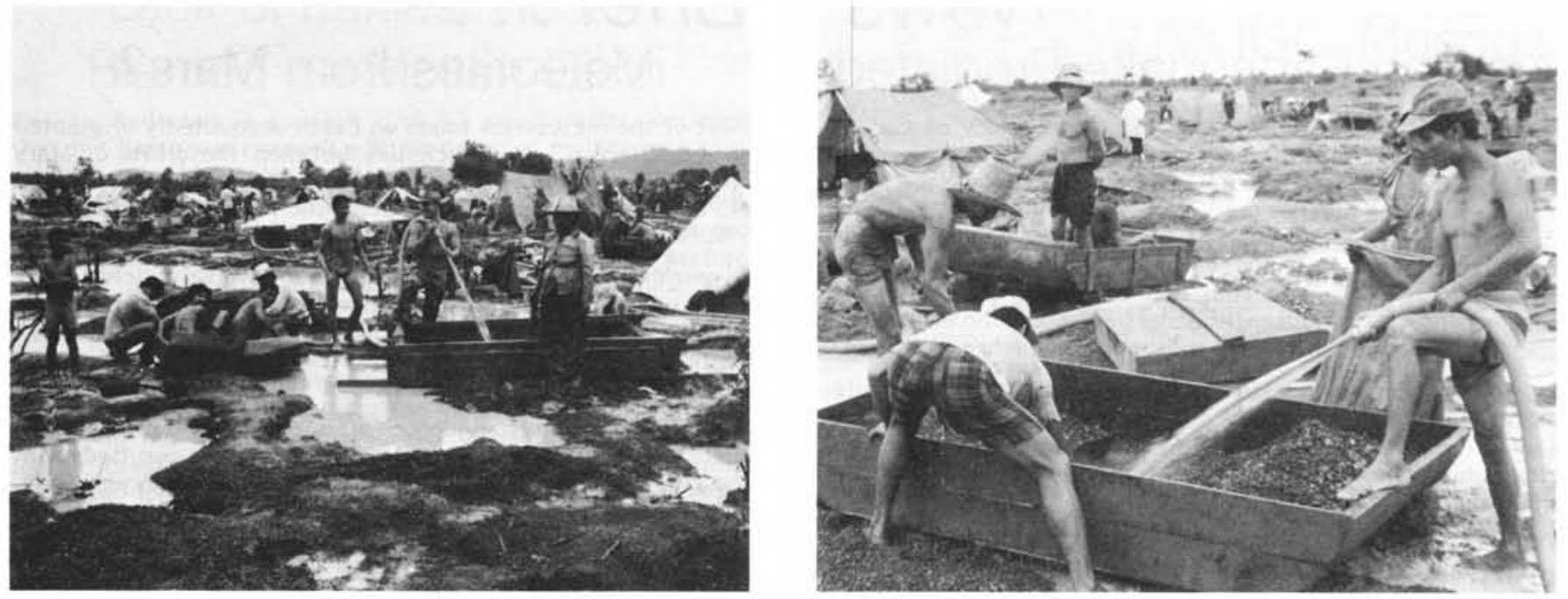

Gold rush area near the town of Kabinburi, E Thailand.

as a repository for all resource information contained on computers. Thus the NRC will occupy the focal point for resource information for all of Thailand.

Although this receiving station is being built by the Government of Thailand with foreign assistance, it is intended to become a regional centre for receiving satellite information, and will therefore have substantial impact on neighbouring countries. The Asian Institute of Technology (AIT), some 50 $\mathrm{km}$ outside of Bangkok, is funded entirely by international efforts and is basically a regional centre for technological training. It will be providing much of the computer training that is required by people from different countries, including Thailand, in the management of resource data. The AIT is an impressive institution with excellent staff who are paid "international" salaries (that is, up to 3 or 4 times greater than the salaries normally paid for government services in Thailand). Not surprisingly, the discrepancy creates some discontent.

At this stage in its development, Thailand could probably get more useful information about its resources from high-level photography done annually or even bi-annually. Aerial photography, however, is not as exotic or topical a field as satellite imagery, and therefore does not attract the same type of support from international groups. Although we recognize the value of promoting satellite imagery, particularly as it straddles national borders and helps to promote

\section{ABOUT THE AUTHORS:}

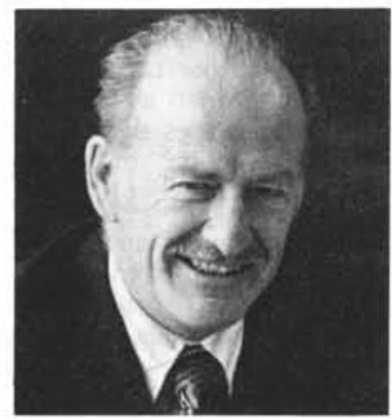

Dr. J.M. Harrison, the first President of IUGS, has had a distinguished career in international science, including service as President of ICSU and as Assistant Director General for Science at Unesco. A former Director of the Geological Survey of Canada, he currently serves as Vice President of the Canadian Commission for Unesco, as advisor to the UN University, and as Chairman of ICSU's Committee on Nuclear Waste Disposal.

EPISODES, Vol. 1981 , No. 3. regional cooperation, we do question, however, the wisdom of funding the exotic at the possible expense of the standard and the most useful.

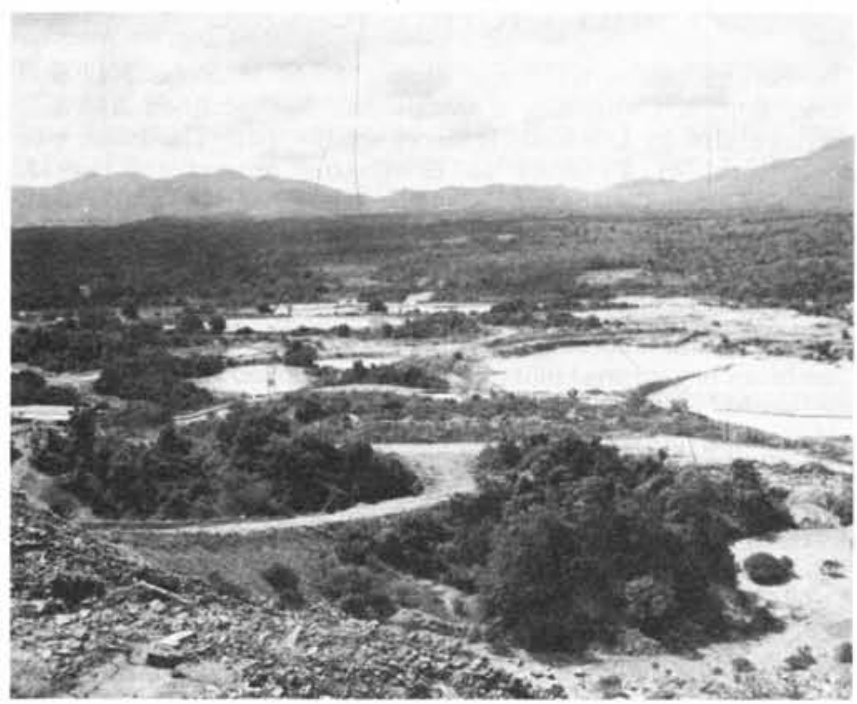

Mined out area, S Thailand.

Dr. P. Leggo is a geochemist with a consulting practice in Cambridge, England. He has done assignments for UN agencies in many areas of the world and has lectured at both British and U.S. universities.

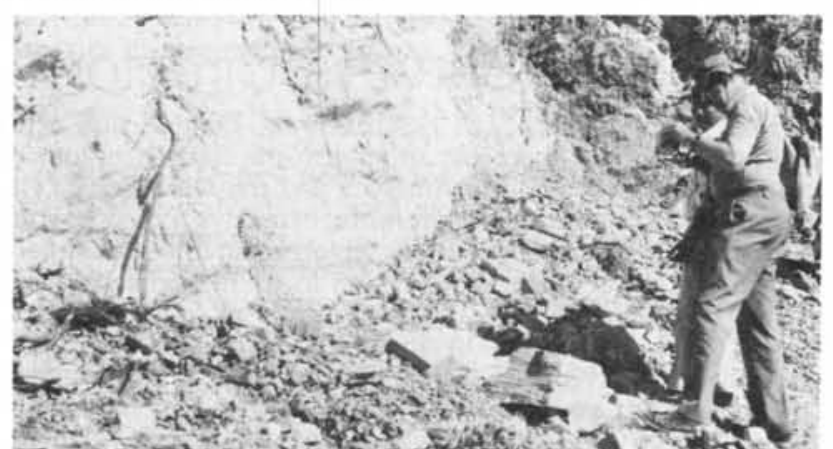

Peter Leggo and a Thai colleague examine contact between the light tin-bearing granite and the dark metasediments at a tin mine in S Thailand. 